\title{
SIGN LANGUAGE RECOGNITION FOR DEAF AND DUMB PEOPLE
}

\author{
Gowri.D ${ }^{1}$, Vidhubala.D ${ }^{2}$ \\ ${ }^{1}$ ME- Applied Electronics, ECE Department, Infant Jesus College of engineering, Tuticorin \\ ${ }^{2}$ ME- Applied Electronics, ECE Department, Infant Jesus College of engineering, Tuticorin
}

\begin{abstract}
Deaf and dumb people use sign language for their communication but it was difficult to understand by the normal people. The aim of this project is to reduce the barrier between in them. The main objective of this project is to produce an algorithm for recognition of hand gestures with accuracy. In this project has a hand gloves model for gesture recognition. MEMS sensor is used to detecting the hand motions based on the stress. This project is used for the deaf and dumb people to communicate with normal people. The hand motions are detected by the MEMS sensor and the values are stored on the microcontroller memory unit. The output voices are previously stored on the voice processor unit. Depends on the hand motions the output will be displayed on the LCD and also played through the speaker.
\end{abstract}

Keywords-MEMS accelerometer, Hand motion comparison, Voice processor, Communication, Sign language

\section{INTRODUCTION}

Sign language is a language which is used for communication between the normal people and disabled people. Sign language relies on sign patterns, i.e., body language, orientation and movements of the arm to facilitate understanding between people. In all around the world about 9.1 billion peoples are deaf and dumb. In their day to day life they faced lot more problems on their communication. In this project is used to reduce the communication gap between the normal people and disabled people. The sign language translator we have developed uses a glove fitted with sensors that can interpret the 26 English letters in American Sign Language (ASL). The glove uses MEMS sensors and accelerometers in different dimensions to gather data on each finger's position and the hand's motion to differentiate the letters.

\section{GESTURE RECOGNITION SECTION}

Gesture is defined as an expressive movement of body parts. The collection of data can be stored on the controller. The purpose of the segmentation algorithm is to find the terminal points of each gesture in a data set of gesture sequence. The data processing unit is used to perform the controlling and transferring function.

\section{DESIGN METHODOLOGY}

For previous year they used image based techniques. By using this technique we require more flexible image processing software. And another method they used cameras for an input device. By using the cameras, the captured gesture has less clarity and also it requires more power to work. The camera based techniques are more expensive.

\section{BLOCK REPRESENTATION}

These sensors are used to reduce the power and cost. It is used to detect the hand motion depends on the stress. And also it is easily embedded with any component or circuit. The hand motions are detected by the MEMS sensor and the values are stored on the microcontroller memory unit. The output voices are previously stored on the voice processor unit. By using LCD the output will be displayed depends on the hand motions and also played through the speaker.

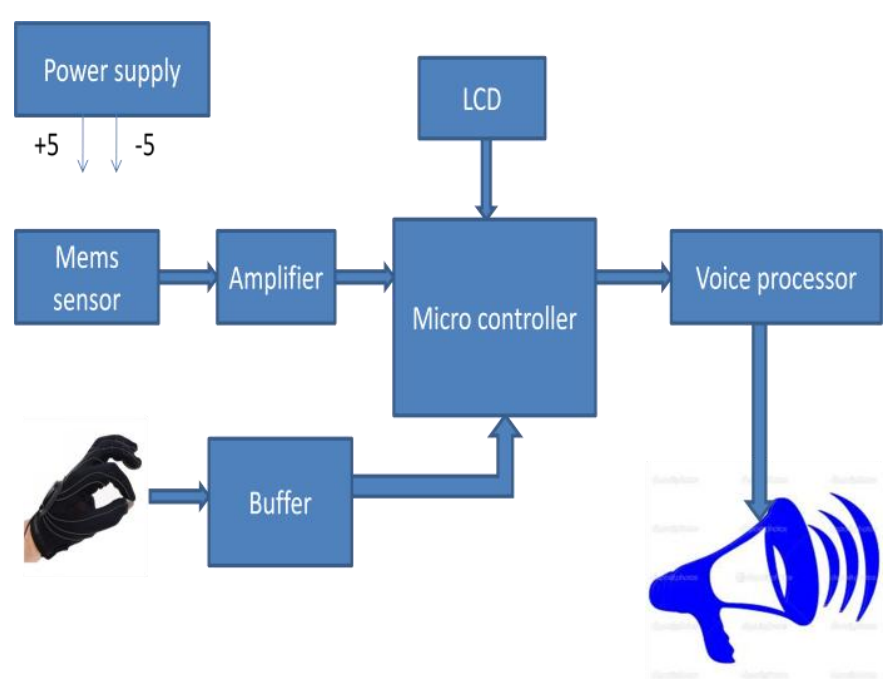

Fig 1: Block diagram

In this block the Power supply unit is used to give power source for all these units. The accelerometer produce three different states of outputs with respect to stress .The accelerometer's output will be given as the input for amplifier. The amplifier amplifies the signal and these signal will goes to the input for microcontroller. The microcontroller's output will be given to voice bank as input. The voice bank produce the voice signal according to the microcontroller's output. Finally the voice output be received through the speaker and text form of the output be displayed on the LCD. 


\section{RESULTS AND DISCUSSIONS}

The system has MEMS sensor for detecting the hand motions. The sensor values are stored on the microcontroller unit. Based on the hand motions the stored outputs are displayed on the LCD and also played through the speaker. Embedded $C$ language is used to write the microcontroller program. MPLAB IDE software is used to develop the system. In this system is detect the hand motions in few seconds and also this system is got $99 \%$ accuracy.

\subsection{Hardware}

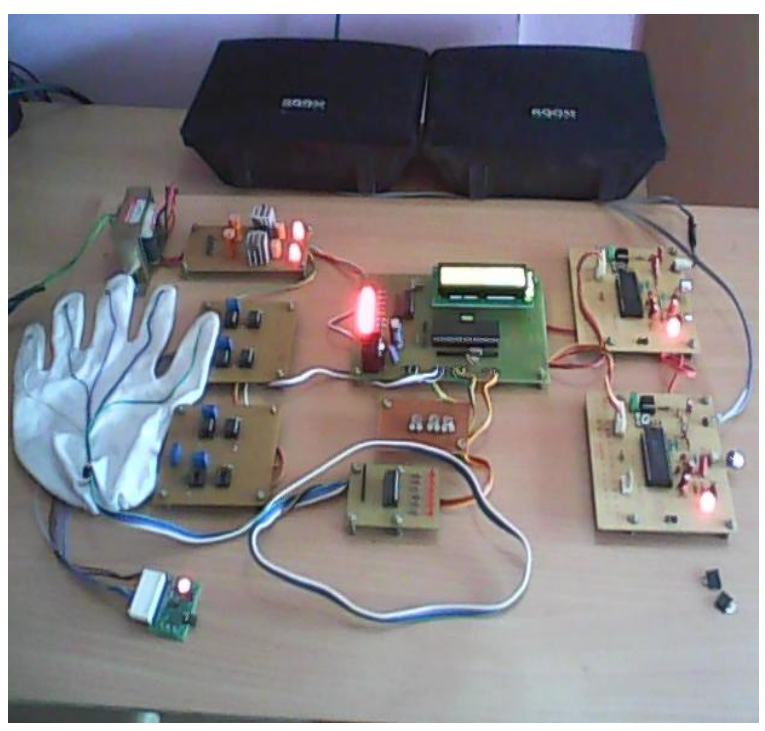

\section{CONCLUSIONS}

In this project describes the working principle of a system which is useful for deaf and dumb people to communicate with the normal people. The system has MEMS sensor for detecting the hand motions. The sensor values are stored on the microcontroller unit. Based on the hand motions the stored outputs are displayed on the LCD and same as play through the speaker.

\section{ACKNOWLEDGEMENTS}

First, I thank the almighty God for his constant blessing through this project work. I am indebted to all the members of teaching staff, non-teaching staff and friends who helped me directly and indirectly in completing this phase of project successfully Last but not the least my family members have been a great source of inspiration and strength to me during the course of this project work. My sincere thanks to them also.

\section{REFERENCES}

[1] Ruize Xu, Shengli Zhou, And Wen J. Li, Mems Accelerometer Based Nonspecific-User Hand Gesture Recognition Ieee Sensors Journal, Vol. 12, No. 5, May 2012

[2] C. M. Bishop (2006), Pattern Recognition and Machine Learning, 1st ed. New York: Springer.
[3] L. Bretzner and T. Lindeberg(1998), "Relative orientation from extended sequences of sparse point and line correspondences using the affine trifocal tensor," in Proc. 5th Eur. Conf. Computer Vision, Berlin, Germany,1406, Lecture Notes in Computer Science, Springer Verlag.

[4] S. S. Fels and G. E. Hinton(1993), "Glove-talk: A neural network interface between a data glove and a speech synthesizer," IEEE Trans. Neural Network., 4, 1, pp. 2-8.

[5] W. T. Freeman and C. D. Weissman (1995), "TV control by hand gestures, "presented at the IEEE Int. Workshop on Automatic Face and Gesture Recognition, Zurich, Switzerland.

[6] K. S. Fu, "Syntactic Recognition in Character Recognition". New York: Academic, 1974, 112, Mathematics in Science and Engineering.

[7] H. Je, J. Kim, and D. Kim (2007), "Hand gesture recognition to understand musical conducting action," presented at the IEEE Int. Conf. Robot \&Human Interactive Communication.

[8] J. S. Lipscomb (1991), “A trainable gesture recognizer," Pattern. Recognition.

[9] W. M. Newman and R. F. Sproull (1979), Principles of Interactive Computer Graphics. New York: McGraw-Hill.

[10] J. K. Oh, S. J. Cho, and W. C. Bang et al. (2004), "Inertial sensor based recognition of 3-D character gestures with an ensemble of classifiers," presented at the 9th Int. Workshop on Frontiers in Handwriting Recognition.

[11] D. H. Rubine (1991), "The Automatic Recognition of Gesture," Ph.D dissertation, Computer Science Dept., Carnegie Mellon Univ., Pittsburgh, PA.

[12] T. Schlomer, B. Poppinga, N. Henze, and S. Boll (2008), "Gesture recognition with a Wii controller," in Proc. 2nd Int. Conf. Tangible and Embedded Interaction (TEI'08), Bonn, Germany.

[13] T. H. Speeter (1992), "Transformation human hand motion for tele manipulation," Presence.

[14] S. Zhou, Q. Shan, F. Fei, W. J. Li, C. P. Kwong, and C. K. Wu et al (2009)., "Gesture recognition for interactive controllers using MEMS motion sensors," in Proc. IEEE Int. Conf. Nano /Micro Engineered and Molecular Systems.

[15] S. Zhang, C. Yuan, and V. Zhang (2008), "Handwritten character recognition using orientation quantization based on 3-D accelerometer," presented at the 5th Annu. Int. Conf. Ubiquitous Systems

[16] T. Yang, Y. Xu, and A. (1994) Hidden Markov Model for Gesture Recognition,CMU-RI-TR-94 10, Robotics Institute, Carnegie Mellon Univ.,Pittsburgh, PA.

[17] S. Zhou, Z. Dong, W. J. Li, and C. P. Kwong (2008), "Hand-written character recognition using MEMS motion sensing technology," in Proc. IEEE/ASME Int. Conf. Advanced Intelligent Mechatronics. 


\section{BIOGRAPHIES}

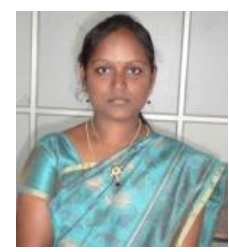

Gowri D received the B.Eng. degree in Electronics and communication engineering from The Anna University of Tamilnadu in 2012. I am currently pursuing the M.E. degree in Applied Electronics at

Tuticorin. the Infant Jesus College of engineering,

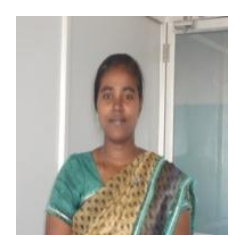

Vidhubala D received the B.Eng. degree in Electronics and communication engineering from The Anna University of Tamilnadu in 2011. She is currently pursuing the M.E. degree in Applied engineering, Tuticorin Electronics at the Infant Jesus College of 